\title{
Increase of scabies infestations, Norway, 2006 to 2018
}

E Amato $^{1,2}$, LS Dansie³, GM Grøneng ${ }^{4}$, HS Blix³ ${ }^{3}$ H Bentele ${ }^{5}$, L Veneti6, P Stefanoff6, E MacDonald 6 , HH Blystad77, A Soleng ${ }^{8}$

1. Department for Vaccine Preventable Diseases, Norwegian Institute of Public Health, Oslo, Norway

2. European Centre for Disease Prevention and Control (ECDC) Fellowship Programme/EUPHEM, Stockholm, Sweden

3. Department of Drug Statistics, Norwegian Institute of Public Health, Oslo, Norway

4. Department of Infectious Disease Epidemiology and Modelling, Norwegian Institute of Public Health, Oslo, Norway

5. Antibiotic Resistance and Infection Prevention, Norwegian Institute of Public Health, Oslo, Norway

6. Department Zoonotic, Food-and Waterborne Infections, Norwegian Institute of Public Health, Oslo, Norway

7. Tuberculosis, Blood Borne and Sexually Transmitted Infections, Norwegian Institute of Public Health, Oslo, Norway

8. Department of Pest Control, Norwegian Institute of Public Health, Oslo, Norway

Correspondence: Amato Ettore (Ettore.Amato@fhi.no)

Citation style for this article:

Amato E, Dansie LS, Grøneng GM, Blix HS, Bentele H, Veneti L, Stefanoff P, MacDonald E, Blystad HH, Soleng A. Increase of scabies infestations, Norway, 2006 to 2018. Euro Surveill. 2019;24(23):pii=190020. https://doi.org/10.2807/1560-7917.ES.2019.24.23.190020

Between October and December 2018, several clinicians in Norway reported an increase in scabies diagnoses. We compared data from the Norwegian Syndromic Surveillance System on medical consultations for mite infestations with scabies treatment sales data to investigate this reported increase. From 2013 to 2018, consultations and sales of scabies treatments had almost increased by threefold, particularly affecting young adults 15-29 years. We recommend to increase awareness among clinicians to ensure timely diagnosis and treatment.

Between October and December 2018, several general practitioners (GPs) and dermatologists reported increasing numbers of patients with scabies to the Norwegian Institute of Public Health (NIPH). In addition, the Deparment for Pest Control at NIPH received many enquiries regarding scabies from members of the public, school nurses, kindergartens and long-term care facilities. As scabies is not notifiable in Norway, we investigated alternate data sources to confirm the increase in order to identify risk groups and target control measures.

\section{Data sources}

We extracted data on consultations from the Norwegian Syndromic Surveillance System (NorSySS) and reported outbreaks from the Norwegian disease outbreak notification system (Vesuv) from 2006 to 2018. NorSySS contains records of consultations at GP offices and outof-hours primary care facilities in Norway. Although there is not a specific diagnosis code for scabies in the NorSySS database, the International Classification of Primary Care (ICPC-2) code 'S72 - infestation mites' [1] was considered the most appropriate proxy for scabies. From Vesuv, we extracted all reported outbreaks of scabies, although reporting of community-based outbreaks of scabies is not mandatory.
We compared NorSySS data with the data on drug use from the Norwegian Drug Wholesales Statistics database and the Norwegian prescription database (NorPD). Wholesales Statistics covers all sales of medicines in Norway, including over-the-counter (OTC), while NorPD includes all prescription drugs dispensed from Norwegian pharmacies. In Norway, the recommended first-line treatment for scabies is topical permethrin ( $5 \%$ cream). Oral ivermectin is prescribed in severe cases or in cases of treatment failure.

\section{Increase in mite infestations and scabies outbreaks}

Between 2006 and 2018, 39,796 consultations for mite infestations were registered in NorSySS. Of these, 26,681 (67\%) were reported from 2013 to 2018. Following an average of 1,815 consultations registered annually from 2006 to 2012, we observed an increasing trend starting in 2013, when 2,457 consultations were registered. The number of consultations for mite infestations during the study period was highest in 2018 at 6,080 consultations, which was almost threefold increase compared with 2012 (Figure 1). Moreover, we have observed that the increasing trend has continued during the first trimester of 2019 , with $60 \%$ more diagnoses compared with the same period in 2018 $(n=2,423$ vs $n=1,512)$.

Between 2006 and 2018, an increase in consultations for mite infestations was observed in all age groups, but the increase was most notable in those aged 15-29 years. The distribution in the age of patients was significantly different (Pearson chi-squared $p$ value 0.001 ) during 2006-12 in comparison with the period 2013-18 with a higher proportion of patients in age group $15-19$ years (14\% vs $21 \%$ ) and $20-29$ years (31\% vs 34\%) between 2013 and 2018. After 2012, the incidence of mite infestations notably increased in patients between 15 and 29 years old. The mean 


\section{FIGURE 1}

Number of mite infestation consultations vs sales of permethrin in Norway, 2006-2018

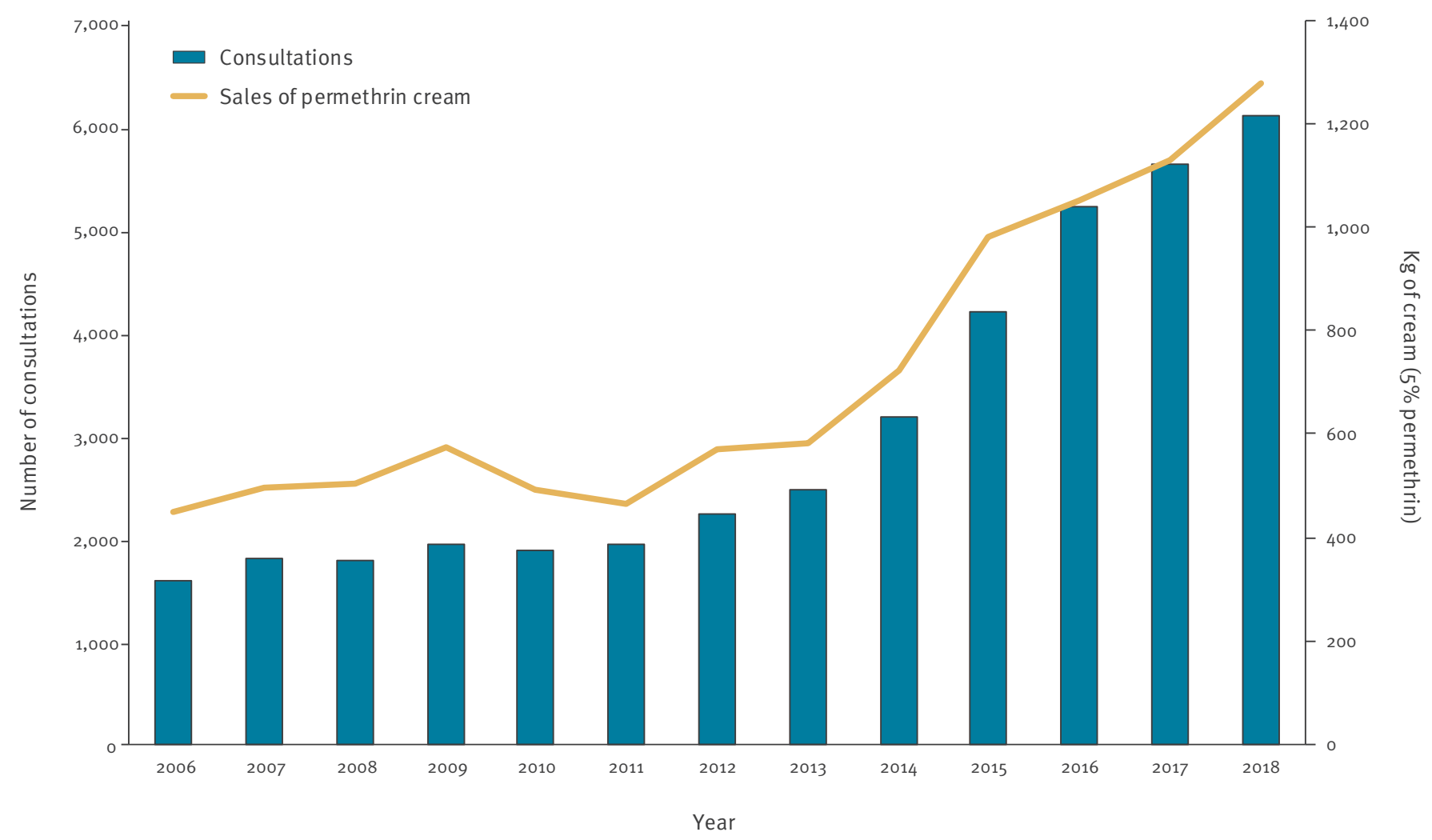

\section{FIGURE 2}

Incidence of mite infestation consultations, by age group, Norway, 2006-2018

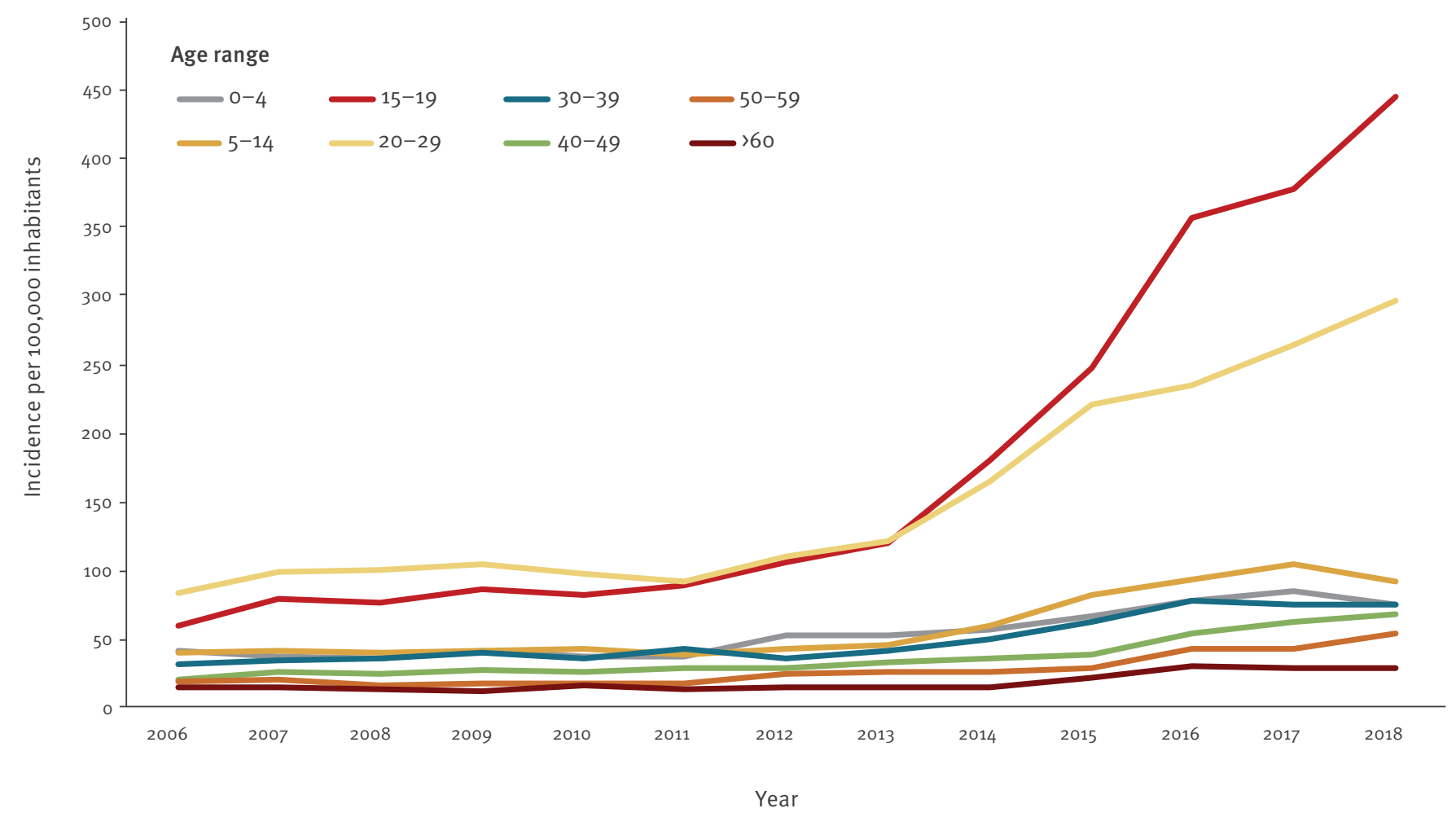


TABLE

Incidence of mite infestation consultations per 100,000 inhabitants, by year and region, Norway, 2006-2018

\begin{tabular}{|l|l|l|l|l|l|l|}
\hline \multirow{2}{*}{ Year } & \multicolumn{5}{|c|}{ Region } & \multirow{2}{*}{ Overall } \\
\cline { 2 - 6 } & North & \multicolumn{1}{|c|}{ Central } & West & South & East & \\
\hline 2006 & 35.4 & 41.8 & 35.9 & 22.5 & 32.5 & 33.9 \\
\hline 2007 & 33.1 & 52.7 & 35.6 & 36.5 & 38.7 & 38.5 \\
\hline 2008 & 44.8 & 48.4 & 31.9 & 41.5 & 36.6 & 37.5 \\
\hline 2009 & 56.5 & 39.3 & 37.5 & 23.9 & 40.7 & 40.3 \\
\hline 2010 & 39.7 & 46.2 & 34.4 & 42.0 & 39.0 & 38.7 \\
\hline 2011 & 39.1 & 35.4 & 36.3 & 46.7 & 40.5 & 39.2 \\
\hline 2012 & 36.3 & 51.5 & 47.3 & 58.8 & 41.9 & 44.6 \\
\hline 2013 & 47.8 & 59.7 & 43.2 & 50.8 & 49.4 & 48.6 \\
\hline 2014 & 68.2 & 62.3 & 64.8 & 62.6 & 58.8 & 61.8 \\
\hline 2015 & 103.4 & 88.8 & 75.7 & 86.6 & 77.5 & 80.9 \\
\hline 2016 & 141.7 & 96.7 & 97.0 & 113.6 & 92.1 & 99.6 \\
\hline 2017 & 161.6 & 104.0 & 91.6 & 101.1 & 105.8 & 106.8 \\
\hline 2018 & 182.3 & 118.6 & 93.5 & 83.0 & 116.5 & 114.8 \\
\hline
\end{tabular}

North region: Finnmark, Troms and Nordland. Central region: Trøndelag. West region: Møre og Romsdal, Sogn og Fjordane, Hordaland and Rogaland. South region: Vest-Agder and AustAgder. East region: Hedmark, Oppland, Buskerud, Akershus, Oslo, $\emptyset$ stfold, Vestfold and Telemark.

annual incidence for the age groups 15-19 years and 20-29 years increased between the periods 2006-12 (81 and 97/100,000, respectively) and 2013-18 (286 and 215/100,000, respectively) (Figure 2). In 2018, the highest incidence was reported in the age groups 15-19 years and 20-29 years (443 and 296/100,000 inhabitants, respectively) with a male:female ratio of 0.9 and 1.4. During 2006-18, mite infestations followed a seasonal pattern with most cases reported during September-November ( $\mathrm{n}=12,734,32 \%)$ and December-February ( $n=10,347,26 \%)$, with the highest number of patients reported between October and December (week 40-49).

Seven small outbreaks, with an average of nine cases (range 2-15), were reported through Vesuv starting from 2018. Scabies outbreaks were recorded in longterm care facilities $(n=3)$, private households $(n=2)$ and other institutions $(n=2)$.

\section{Increase in sales of scabies treatments}

Data from the Wholesales Statistics showed increasing sales of permethrin starting in 2014, with the largest amount of cream sold in $2018(1,300 \mathrm{~kg})$. GPs prescribed around $10 \%$ of sold permethrin and the remaining amount was distributed through over-the-counter sales. Sales of permethrin followed a similar trend as the NorSySS data during the period 2006-18 (Figure 1).

Although ivermectin was not frequently prescribed, we also observed an increasing trend in ivermectin treatment prescriptions registered in NorPD, with an increase first observed in 2012. Prescriptions then
FIGURE 3

Incidence of mite infestation consultations per 100,000 inhabitants, by county, Norway, 2018

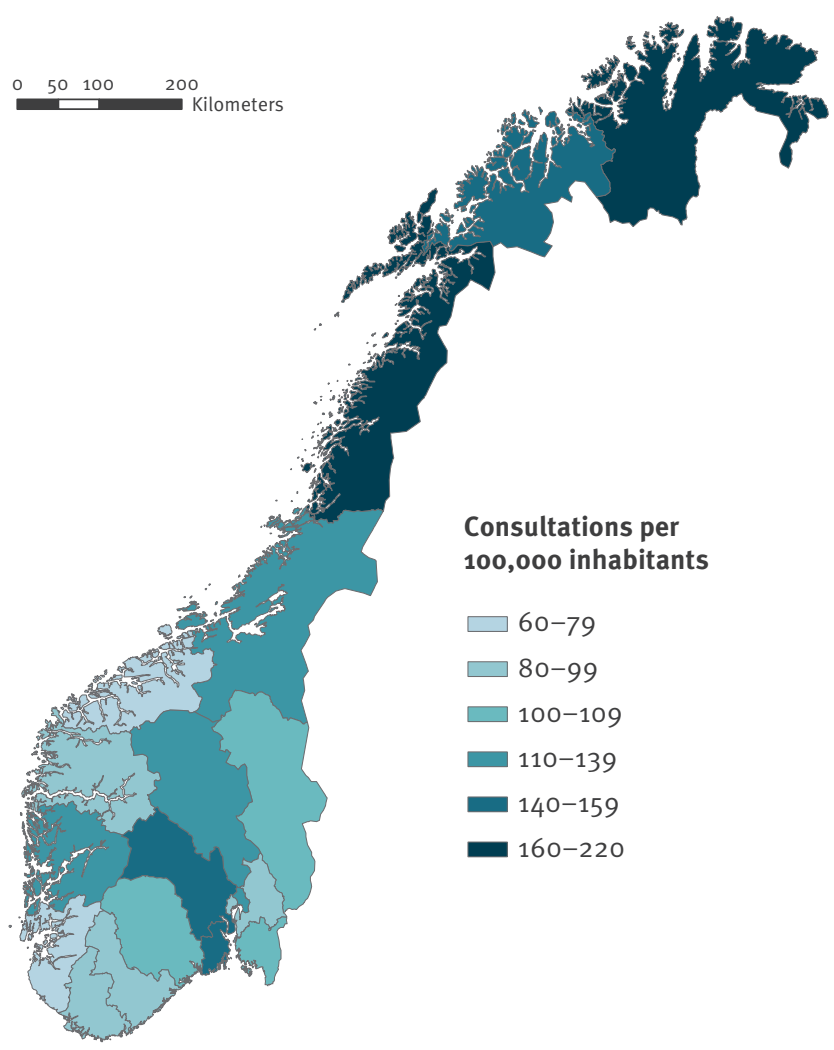

decreased until 2014 before rising rapidly to the highest observed level of sales during the study period in 2018. According to data from the Norwegian Medicines Agency (NoMA), the main indication for prescribing ivermectin since 2016 was treatment of scabies ( $n=1,055$ prescriptions, $73.2 \%$ ) or unsuccessful use of permethrin ( $n=96$ prescriptions, $6.7 \%$ ).

\section{Geographical distribution of mite infestations}

An increasing incidence of mite infestation consultations was observed in all Norwegian regions during the period 2006-18 (Table 1). In 2018, the highest incidence of consultations was reported in the northern region, followed by central, east, west and south regions with incidences of $182.3,118.6,116.5,93.5$ and 83.0 cases per 100,000 inhabitants, respectively (Figure 3).

\section{Discussion and conclusions}

Scabies is a parasitic skin infestation caused by Sarcoptes scabiei variant hominis mite that is usually spread through prolonged skin-to-skin contact. Infestation with scabies mites results in an intensly itchy skin eruption consisting of papules, nodules and vescicles [2]. Although scabies is a very common disease worldwide, the prevalence is unknown. 
Population-based data from Europe are lacking since scabies is not a notifiable disease in most European countries [3]. Nevertheless, the increase in consultations, along with the simultaneous increase in sales of scabies treatments and outbreaks detected in Norway, suggest an increase in incidence of scabies since 2013. In recent years, an increasing number of cases has also been reported in other European coutries, including Croatia and Germany $[4,5]$. The seasonal trend we observed is also consistent with other European countries where scabies is more frequently reported in wintertime as cool and moist environments increase the survival of mites $[6,7]$.

Scabies is commonly reported in children (0-9 years old), young adults (10-19 years old) and elderly people ( $>80$ years old) [8]. The Norwegian data indicate few consultations (0.9\%) reported among elderly people and highest proportion of consultations (58.1\%) among the age groups $15-19$ and $20-29$ years between 2006-18. Although scabies has been more frequently described in females than males [8-11], we observed a male to female ratio of 1.4:1 in the age group 20-29 years. Further research is currently underway to explain the factors associated with transmission in these groups in Norway. In some European countries, migration and travel have been investigated as factors possibly associated with scabies $[4,5,12]$, particularly in the context of screening of asylum seekers upon arrival and mass treatment of scabies in reception centers $[13,14]$.

Given that scabies infestations occur after prolonged skin-to-skin contact we cannot exclude that transmission through sexual contact may also explain the increased incidence among young adults [15]. Mellanby et al. [16] showed that indirect transmission through furniture and fomites is also plausible, but it is unlikely to play a significant role unless the person is heavily infested (e.g. immunocompromised persons with crusted scabies). Additionally, we cannot exclude that the increase observed in the first trimester of 2019 could have been influenced by national media attention as this was a widely covered topic in Norway.

There are several limitations in this investigation. The reported incidence of consultations is likely to overestimate scabies infestations. First, the ICPC-2 code S72 can include symptoms caused by other types of mites. Second, the lack of microscopic detection of mites decreases the predictive value of clinical diagnosis [4]. Third, physicians can record recurrent infestations and treatment of close contacts under the same code. Data on sales of scabies treatments may also reflect the number of treatments for diagnosed scabies in addition to the number of close contact treatments.

Although we cannot yet conclude on the reasons for the demonstrated increase, clinicians should be vigilant to ensure scabies is being appropriately diagnosed and treated taking also into account that itching can persist for 2-4 weeks after the end of treatment, in some cases even longer [17]. As scabies is largely diagnosed on clinical grounds since there are no standardised laboratory tests available [2], treatment failure may occur due to wrong diagnosis, incorrect use of cream, or improper intake of oral treatments [4]. Therefore, early diagnosis confirmations and proper treatment are critical for avoiding the spread of infestation and outbreaks [18].

\section{Acknowledgements}

We would like to thank Harald Pors Muniz (Communication Department, Norwegian Institute of Public Health) for his work. We also gratefully acknowledge local and international EUPHEM coordinators for guidance during this study and Dr. Aftab Jasir for reviewing the manuscript.

\section{Conflict of interest}

None declared.

\section{Authors' contributions}

$E A, H S B, H B, H H B, E M$ and $A S$ designed the study. EA and EM wrote the manuscript. LSD and HSB were responsible for the drugs statistics data. GMG was responsible for the Norwegian syndromic surveillance data. EA, LV and PS were involved in epidemiological data analysis and interpretation. AS was responsible for public communication as spokesperson during outbreak investigation. All authors were involved in developing the manuscript, and commented and agreed upon the final version.

\section{References}

1. WICC. (1998) International Classification of Primary Care, ICPC2 Oxford University Press, Oxford.

2. Chandler DJ, Fuller LC. A Review of Scabies: An Infestation More than Skin Deep. Dermatology. 2019;235(2):79-90. https://doi.org/10.1159/000495290 PMID: 30544123

3. Romani L, Steer AC, Whitfeld MJ, Kaldor JM. Prevalence of scabies and impetigo worldwide: a systematic review. Lancet Infect Dis. 2015;15(8):960-7. https://doi.org/10.1016/S14733099(15)00132-2 PMID: 26088526

4. Sunderkötter C, Aebischer A, Neufeld M, Löser C, Kreuter $A$, Bialek R, et al. Increase of scabies in Germany and development of resistant mites? Evidence and consequences. J Dtsch Dermatol Ges. 2019;17(1):15-23. https://doi.org/10.1111/ ddg.13706 PMID: 30480868

5. Lugović-Mihić L. The increase in Croatia's scabies incidence: How did refugees and traveling contribute? Travel Med Infect Dis. 2019: S1477-8939(19)30033-X.

6. Arlian LG, Morgan MS. A review of Sarcoptes scabiei: past, present and future. Parasit Vectors. 2017;10(1):297. https:// doi.org/10.1186/s13071-017-2234-1 PMID: 28633664

7. Liu JM, Wang HW, Chang FW, Liu YP, Chiu FH, Lin YC, et al. The effects of climate factors on scabies. A 14 -year populationbased study in Taiwan. Parasite. 2016;23:54. https://doi. org/10.1051/parasite/2016065 PMID: 27905271

8. Lassa S, Campbell MJ, Bennett CE. Epidemiology of scabies prevalence in the U.K. from general practice records. $\mathrm{Br} J$ Dermatol. 2011;164(6):1329-34. https://doi.org/10.1111/j.13652133.2011.10264.x PMID: 21574970

9. Shrank AB, Alexander SL. More cases of scabies. BMJ. 1968;1(5589):445. https://doi.org/10.1136/bmj.1.5589.445-a PMID: 5639636

10. Downs AM, Harvey I, Kennedy CT. The epidemiology of head lice and scabies in the UK. Epidemiol Infect. 1999;122(3):471-7. https://doi.org/10.1017/S0950268899002277 PMID: 10459652 
11. Lapeere H, Naeyaert JM, De Weert J, De Maeseneer J, Brochez L. Incidence of scabies in Belgium. Epidemiol Infect. 2008;136(3):395-8. https://doi.org/10.1017/ So950268807008576 PMID: 17506916

12. Di Meco E, Di Napoli A, Amato LM, Fortino A, Costanzo G, Rossi A, et al. Infectious and dermatological diseases among arriving migrants on the Italian coasts. Eur J Public Health. 2018;28(5):910-6. https://doi.org/10.1093/eurpub/cky126 PMID: 30010744

13. Beeres DT, Ravensbergen SJ, Heidema A, Cornish D, Vonk $M$, Wijnholds LD, et al. Efficacy of ivermectin mass-drug administration to control scabies in asylum seekers in the Netherlands: A retrospective cohort study between January 2014 - March 2016. PLoS Negl Trop Dis. 2018;12(5):eooo6401. https://doi.org/10.1371/journal.pntd.0006401 PMID: 29771941

14. Isenring E, Fehr J, Gültekin N, Schlagenhauf P. Infectious disease profiles of Syrian and Eritrean migrants presenting in Europe: A systematic review. Travel Med Infect Dis. 2018;25:6576. https://doi.org/10.1016/j.tmaid.2018.04.014 PMID: 29702253

15. Sunderkötter C, Feldmeier H, Fölster-Holst R, Geisel B, KlinkeRehbein S, Nast A, et al. S1 guidelines on the diagnosis and treatment of scabies - short version. J Dtsch Dermatol Ges. 2016;14(11):1155-67. https://doi.org/10.1111/ddg.13130 PMID: 27879074

16. Mellanby K. The development of syntoms, parasitic infection and immunity in human scabies. Parasitology. 1944;35(04):197206. . https://doi.org/10.1017/So031182000021612

17. Sladden MJ, Johnston GA. Common skin infections in children. BMJ. 2004;329(7457):95-9. https://doi.org/10.1136/ bmj.329.7457.95 PMID: 15242915

18. Lay CJ, Wang CL, Chuang HY, Chen YL, Chen HL, Tsai SJ, et al. Risk factors for delayed diagnosis of scabies in hospitalized patients from long-term care facilities. J Clin Med Res. 2011;3(2):72-7. https://doi.org/10.4021/jocmr520w PMID: 21811533

\section{License, supplementary material and copyright}

This is an open-access article distributed under the terms of the Creative Commons Attribution (CC BY 4.0) Licence. You may share and adapt the material, but must give appropriate credit to the source, provide a link to the licence and indicate if changes were made.

Any supplementary material referenced in the article can be found in the online version.

This article is copyright of the authors or their affiliated institutions, 2019. 